\title{
TYPOGRAPHICAL DEVICES IN SUBTITLING (A CASE STUDY OF ENGLISH AND RUSSIAN SUBTITLES)
}

\author{
IRINA ZIYAZOVA \\ Nizhnevartovsk State University \\ irina_cloud@mail.ru
}

\begin{abstract}
The paper examines the role of typographical devices in subtitling practices. As subtitling is significantly determined by its temporal and spatial constraints, the verbal part of a subtitle may be rather condensed and incomplete for perception, which requires additional means to modify meaning-making processes and add up information. The research gives a systematic account of typographical devices and their functions in a subtitled filmic text. The common graphical devices featured are typefaces, colour, punctuation marks, and numeric signs. The performed analysis showed that typographical devices do not only assist in dealing with technical considerations, but they may also serve as means of intersemiotic cohesion linking subtitles with visual or acoustic-or both-components of a film and enabling their functional cooperation. The drawn conclusions allow to state that graphical devices in subtitling possess such functions as they contribute to intersemiotic texture of a subtitled filmic text; help to manoeuvre in spatial and temporal circumstances; enhance reading and comprehending.
\end{abstract}

KEYWORDS: typographical devices, non-verbal signs, subtitling, subtitled filmic text, intersemiotic cohesion.

\section{INTRODUCTION}

Subtitling due to its well-known temporal and spatial constraints may frequently lead to a significant condensation of the target text. The diasemiotic nature of subtitling, as H. Gottlieb characterizes it (Gottlieb 2005: 20), observes the transformation of acoustically rendered speech in L1 into visually presented speech in L2. Along this crossing over from oral to written, the original message may undergo various and sometimes numerous changes, i.e. some lexical units may be omitted, others may become simplified or paraphrased, sentences may be united or vice versa split, etc. Having little space and exposure time at his/her disposal, a subtitler has to compress the target text, which as a result may seem as a rather incomplete transfer of information. For the viewer to recover the necessary bits, subtitlers resort to non-verbal means, among which graphical devices are apparently a matter of paramount importance in subtitling.

The article attempts to give a systematic account of commonly used graphical devices in subtitling and their functions in a subtitled filmic text. Within the research framework, a subtitled filmic text is understood as a multimodal text with an additional semiotic constituent, viz. subtitles, incorporated into its complex semiotic composition by means of intersemiotic 
cohesion and where synergetic interaction of semiotic components determine meaning-making processes and provide a coherent functional whole.

Before going further though, it seems imperative to take a closer look at this medium in which subtitles function.

\section{MEANING-MAKING IN A SUBTITLED FILMIC TEXT}

One of the reasons subtitling stands out amidst other translation practices is the fact that subtitles function in a singular medium. As J. Pedersen aptly noticed, "subtitles differ from the common notion of target text, because they are part of a polysemiotic text" (Pedersen 2005: 13).

A film is an audiovisual product and polysemiotic per se. First of all, the notion of a polysemiotic (or multimodal) text implies concurrence of several semiotic resources or modes (Baldry and Thibault 2006; Chaume 2004: 17), which build the composition of such a text. Second of all, the meaning-making processes in polysemiotic texts are determined by the intersemiotic and interdependent operation of all the modes. In his studies of how the interaction of semiotic resources affords new forms of informational complexity in hypermedia, J.L. Lemke proclaims that "the meaning potential, the meaningresource capacity, of multimodal constructs is the logical product, in a multiplicative sense, of the capacities of the constituent semiotic resource systems" (Lemke 2002: 303). And it does appear felicitous in reference to a subtitled filmic text, since subtitles taken in isolation would not make sense, as would not the original film to a non-native viewer. It is only the intersemiotic cooperation that launches the processes of meaning-making. Most important of all, subtitles are complementary towards a film and must be correctly introduced and anchored in the semiotic composition of a filmic text, which to a certain extent can be provided by graphical devices. According to our theory (Ziyazova 2015), graphical devices may serve as means of intersemiotic cohesion and make heterogeneous semiotic elements hold together and enable a constructed meaning

\section{THE VALUE OF TYPOGRAPHICAL DEVICES}

The fact that typographical elements can realise textual meaning was highlighted by T. van Leeuwen:

Typography can demarcate the elements, the 'units', of a text and express their degree of similarity or difference as textual elements, and it can foreground key elements of a text and background less important elements. Many typographical signs that are not letter forms realise textual meaning, the most obvious example being punctuation marks - and they, too, are now rapidly developing new uses and new signs (Leeuwen 2006: 143). 
The author also accentuates the multimodal nature of typography as it is "integrated with other semiotics means of expression such as colour, texture, three-dimensionality, and movement" (Leeuwen 2006: 144). E.E. Anisimova, in her studies of non-verbal means-typography inclusive-that accompany a written text, defines them as paralinguistic means. Paralinguistics is a branch of linguistics that studies non-verbal means that accompany speech and along with verbal means carry meaningful information. The scholar claims that from text linguistics' perspective the analysis of paralinguistic devices is concerned with text-forming processes, the role of paralinguistic means in reaching pragmatic purposeful effects and a necessity to retrieve more complete text information (Anisimova 2003: 6). According to T.M. Nikolaeva, there are three types of paralinguistic means: phonatory means (voice level, pitch, rate of speech, pronunciation features), kinetic means (gestures, facial expressions, postures), graphic means (ways of writing, hand-writing, special uses of symbols and characters, etc.) (Nikolaeva 1998: 367).

The main objective of the present research is to study typographical means in subtitling, however as we shall see they can also convey some prosodic features and refer to some kinetic aspects. The practical analysis below is carried out on the basis of the 2014 English film The Grand Budapest Hotel with English and Russian subtitles.

\subsection{Font}

Pertaining to fonts and typefaces, the subtitling norms focus on a major issue here, which is that of legibility. As many scholars point it out, it is preferable to use typefaces without serifs to avoid visual complexity and a decrease in legibility (Karamitroglou 1997, Diaz Cintas and Remael 2007).

There are also commonly used font designs to make subtitles visually salient on particular purposes.

\subsubsection{Italics}

Italics are not used in subtitling for the deaf and hard-of-hearing but possess several functions in both intralingual and interlingual subtitling. The main function of cursive subtitles is to reflect off-screen speech. For instance, the following shot represents a splendid view of the Grand Budapest Hotel and there is a background voice that belongs to the narrator who is unfolding the story. 


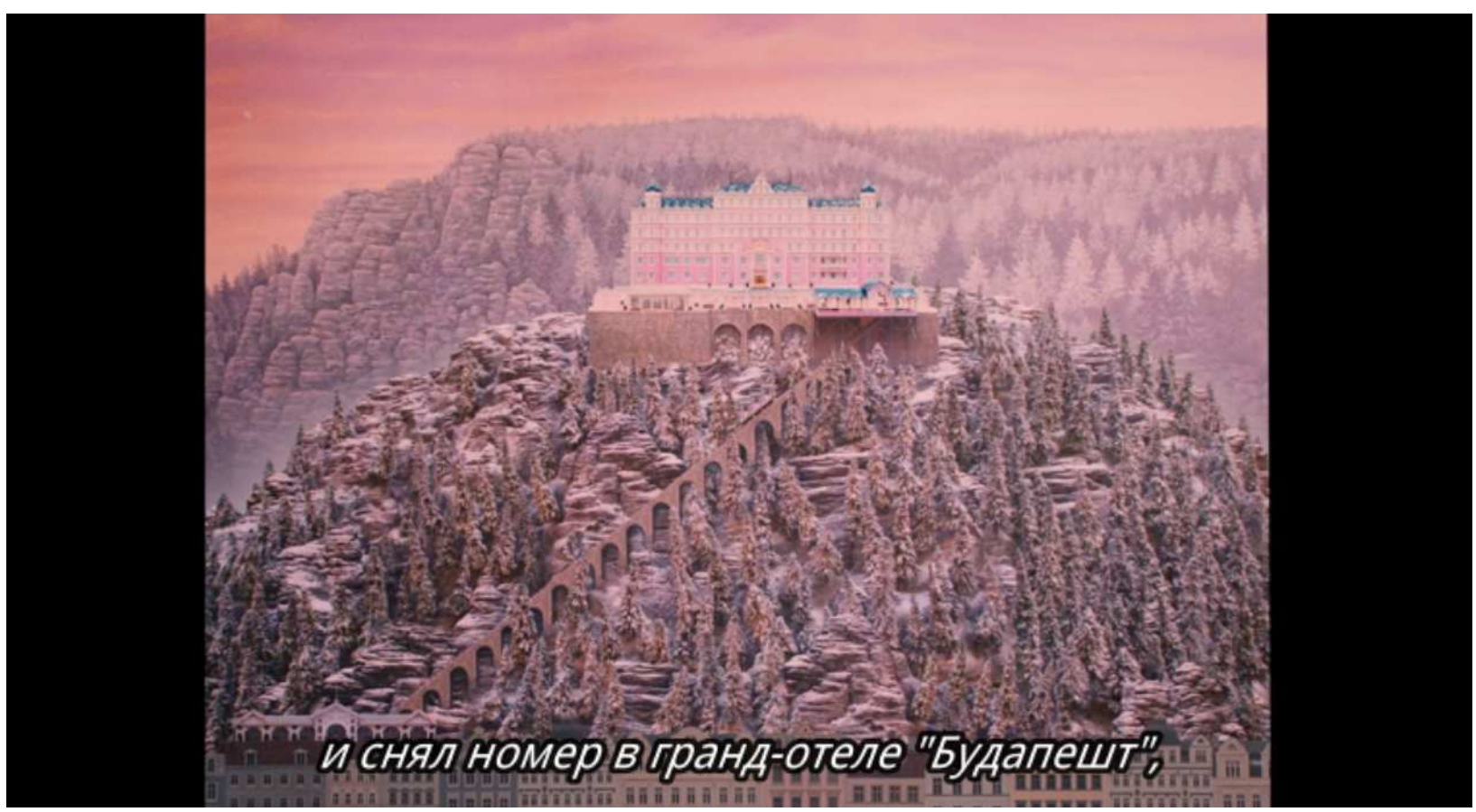

As H. Gottlieb mentions, the prosodic features cannot be truly retrieved from subtitles (Gottlieb 2005: 20), but such a graphic device as italics draws and directs the viewer's attention to something particular in the soundtrack. The viewer goes from cursive writing to acoustic elements, which provides a cohesive effect.

Taking a closer look at the next screenshot, there is a rather singular case to be discovered. It exemplifies a partially cursive subtitle.

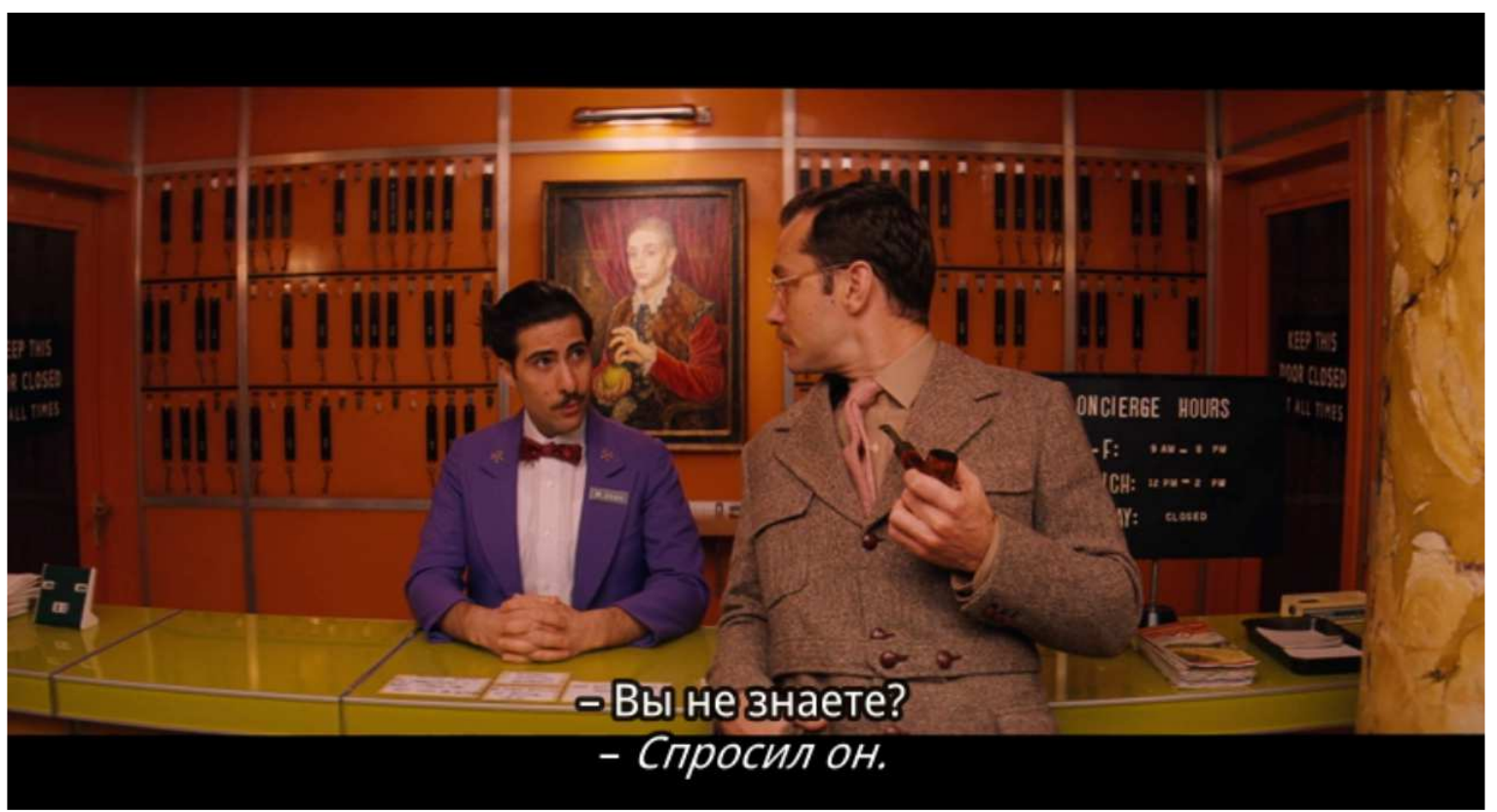

The subtitle is a two-liner where each line is introduced with a dash.

- Don't you know?
- He asked.
- Вы не знаете?

- Спросил он. 
Speaking of dashes and some other punctuation marks, it is worth mentioning that the punctuation signs may function cohesively as well. The use of dashes here indicates an utterance exchange and informs the audience that the first line belongs to one character, whereas the second line to the other. There is also a difference in typefaces to be discerned-the first line is regular and the second one is cursive. In effect, the screenshot shows the narrator who is continuing his inner monologue and then is interrupted by the character in the background. Thus, a distinguished writing refers to the discourse elements of the film and its inner reality.

The following shot illustrates a notable case of using italics since is not that for off-screen expressions.

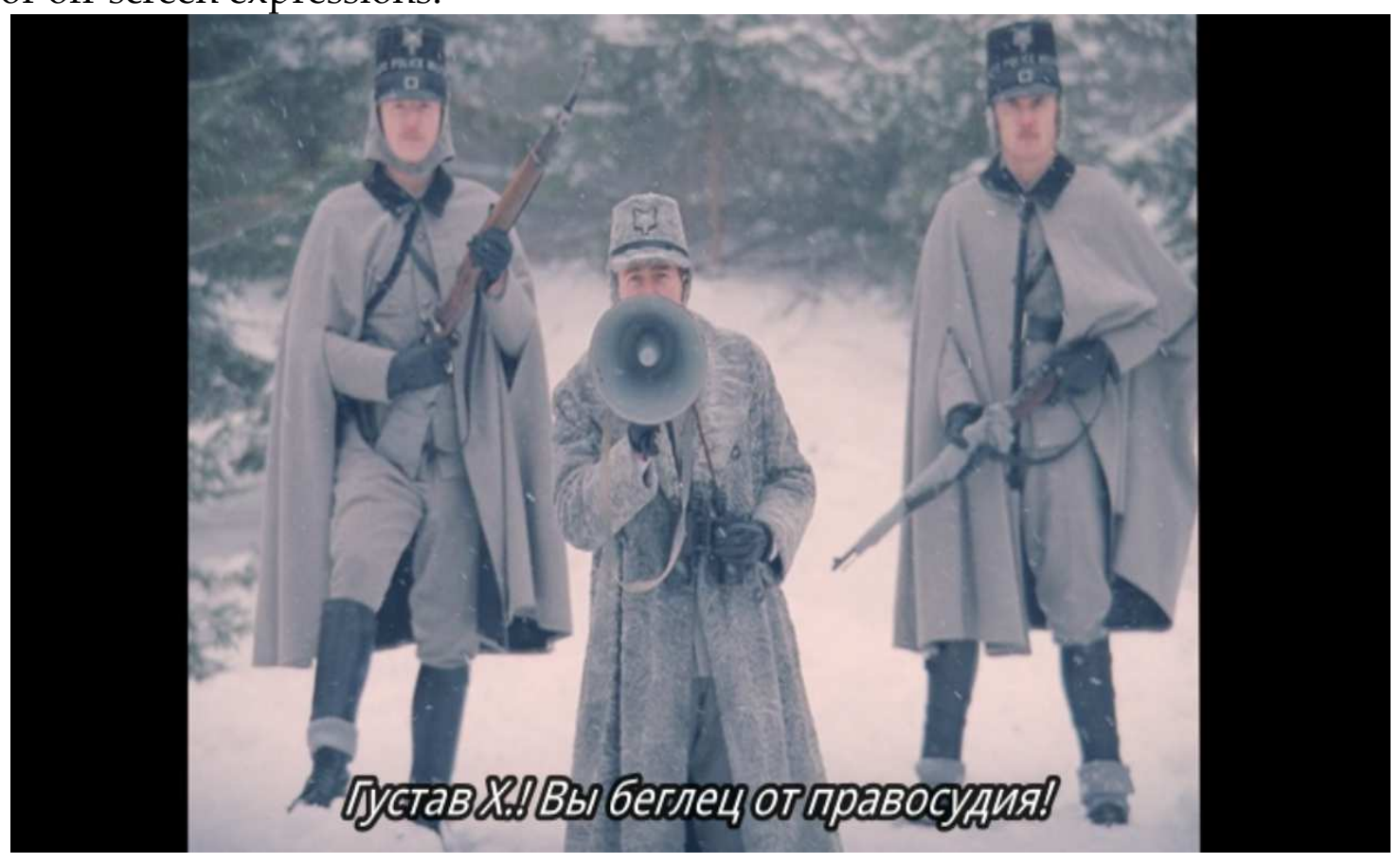

Italic subtitles are used here to render on-screen speech, which is though somewhat peculiar.

\begin{tabular}{|l|l|}
\hline $\begin{array}{l}\text { Gustave H! You are a } \\
\text { fugitive from justice! }\end{array}$ & Густав Х.! Bъь беглец, от правосудия! \\
\hline
\end{tabular}

The character speaking-though zoomed in-is standing across the ravine and using a megaphone so that he could be heard by the main characters. Thus, cursive writing refers not only to specific prosodic aspects of the utterance, but also to the proxemic signs that "deal with the distance of the characters to each other, as well as the distance from the characters to the camera" (Chaume 2004: 20).

As was seen above, italics appear to have cohesive properties as they may connect subtitles with acoustic or visual elements of the film and therefore contribute to the intersemiotic texture. 


\subsubsection{Capitalisation}

Capitalised subtitles tend to render short visually presented captions like road signs, graffiti, newspaper headlines, banners, etc. (Diaz Cintas and Remael 2007: 118). The given screenshot below demonstrates a view of an ending piste and there is no acoustic message accompanying.

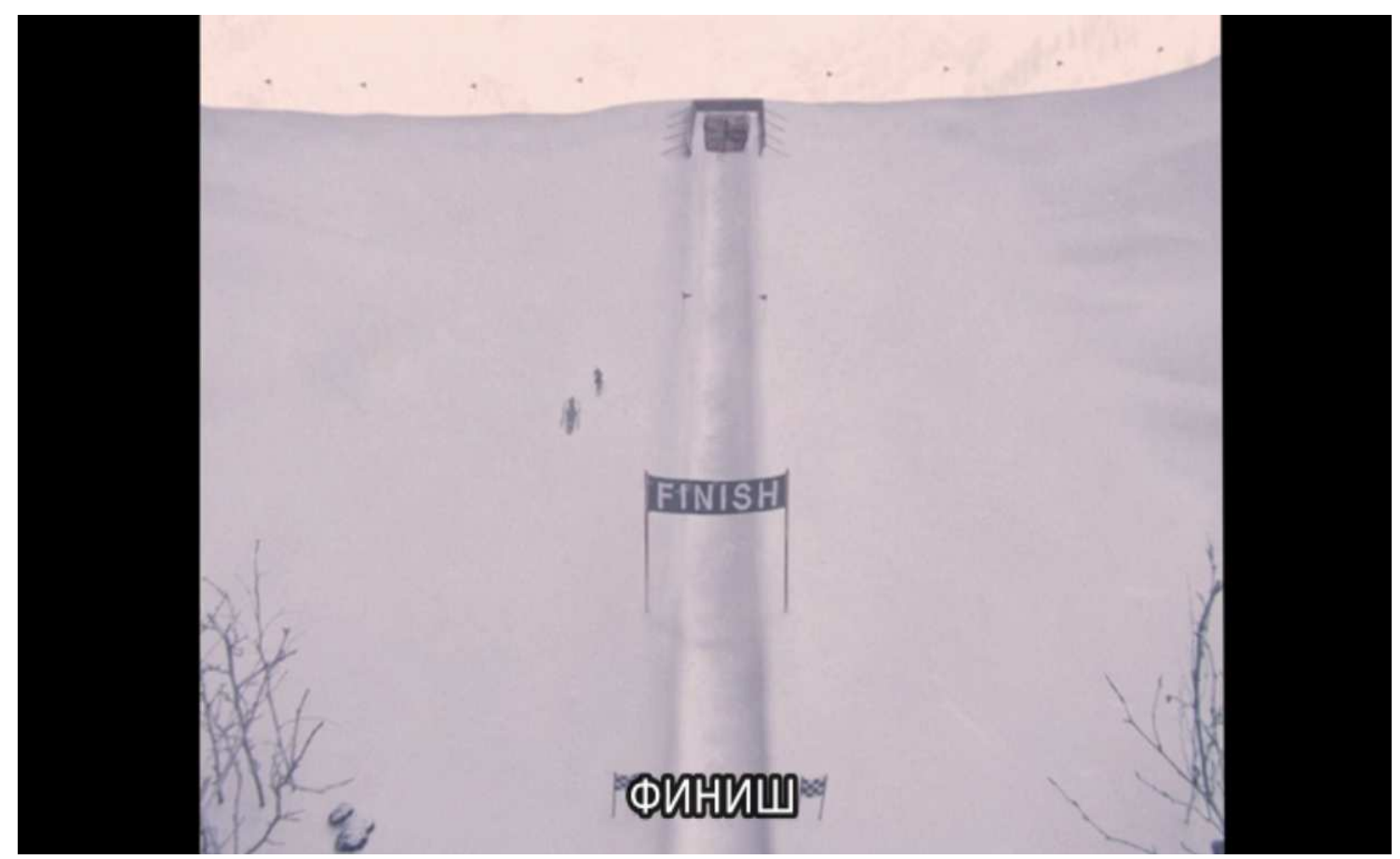

Such conditions encourage the viewer to correlate the translation with a diegetic element presented on the screen. More specifically, capitalization in subtitling serves as a sort of graphical reference, namely it ties the subtitle with a visual semiotic component of the filmic text.

The fact that capitalized subtitles may be employed to graphically represent the aural characteristics of the spoken dialogue, i.e. for shouted words, was examined by $\mathrm{R}$. McClarty in her research of creative subtitling (McClarty 2011: 148). Taking that under consideration, we see that capitalized subtitles may also perform this function of referring to the prosodic aspect of an uttered expression.

\subsection{Colour}

The conventions of interlingual and intralingual subtitling prescribe to colour subtitles white. J. Diaz Cintas and A. Remael mention that yellow may be exploited as well "when subtitling black and white films, so that the contrast between image and text is sharper" (Diaz Cintas and Remael 2007: 84). The main concern in the use of colour in subtitling is -on a par with font- that of 
legibility. In similar respect, F. Karamitroglou claims that subtitles should be coloured pale white, and not bright white as it will be "tiring to the viewer's eye" (Karamitroglou 1997: 3).

In subtitling for the deaf and hard of hearing it is though common to use coloured subtitles. This way particular colours would indicate particular characters; hence colour in this context may exhibit a cohesive function too.

Studying functional potential of creative subtitles, R. McClarty underlines that colour and subtle effects could be added "to indicate the emotional or physical state of a particular character: for example, text with low opacity for a character who is weak or tired" (McClarty 2011: 144).

\subsection{Numeric signs}

As it gets down to rendering numbers, there are two ways of doing so- using alphabetical characters or numeric signs. The biggest advantage of using numeric signs is that they take less space in a subtitle:

I worked six days each week plus a half-day Sunday,
Я работал 6 дней в неделю, полдня в воскресенье.

The Russian subtitle contains a number 6, which is plausible since it requires less space than five characters of its alphabetical writing "uecms". However, if a situation allows it, spelling is preferred:

Six, Igor. Шестой, Игорь.

Both in English and in Russian the general stylistic rules state that the numbers from one to ten are traditionally written in letter forms, whereas the succeeding numbers should be presented in digits.

However, what is of great relevance within the framework of this research is situations when there are numeric signs presented on screen, for instance, as the following screenshot illustrates a diegetic caption. 


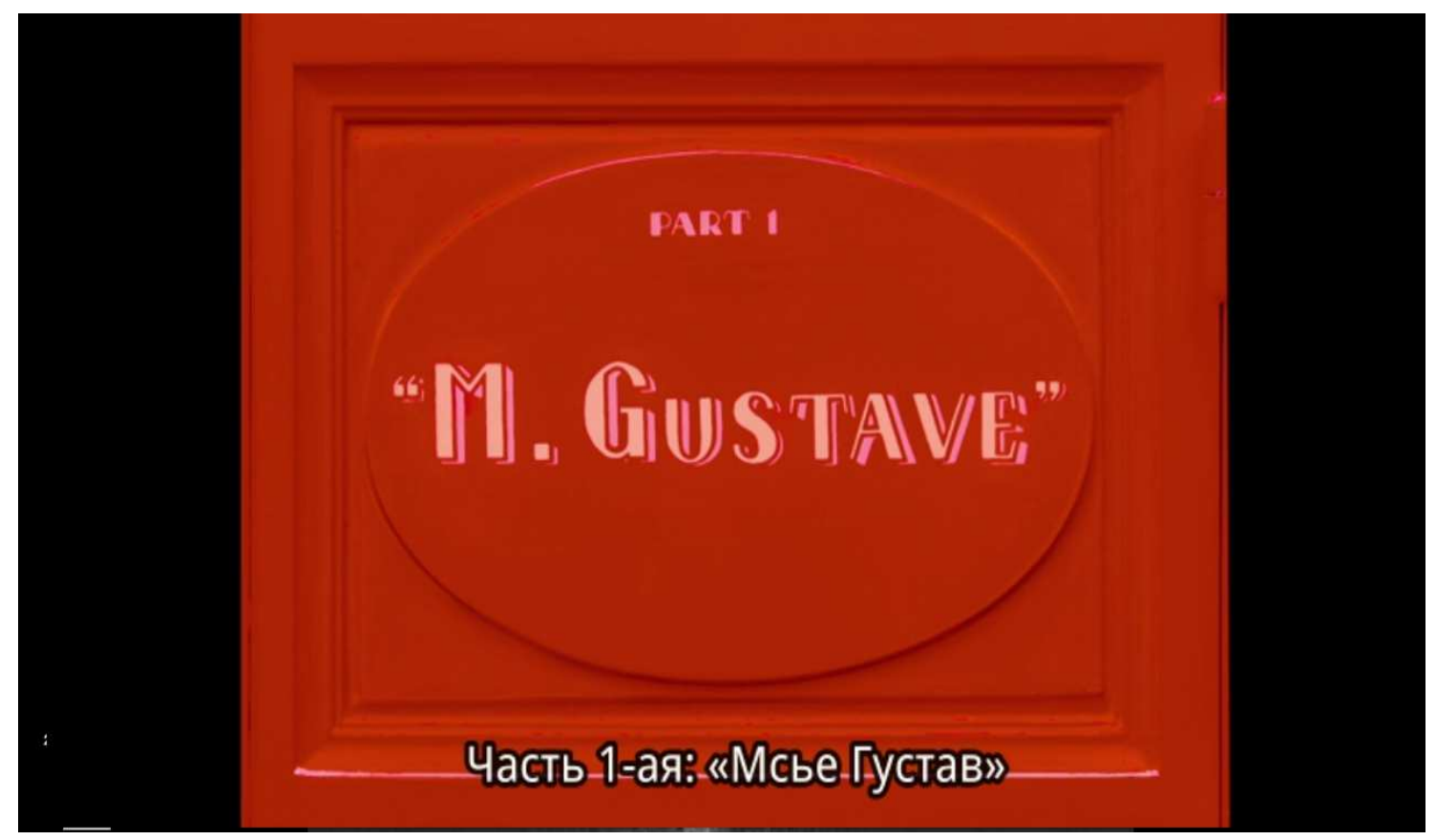

Thus, the use of numeric writing of a number in the Russian subtitle is obligatory since the viewer connect 1 located in the subtitle with 1 presented in the shot.

\section{CONCLUSIONS}

The article strived to give a systematic account of typographical devices in subtitling and their functions respectively. The present research examined here various typographical means such as font, colour, and numeric signs. The analysis of the norms and functions that typography carries in subtitling practices makes it contextually-justified to draw the following conclusions:

- Graphical signs can realize textual meaning and possess functional potential;

- Typographical devices like font and color contribute to legibility and therefore provide optimum conditions for the viewer to read and comprehend meaning;

- Typographical devices such as numeric signs may significantly save up the given space in a subtitle and increase the viewer's reading speed;

- Graphical signs may serve as means of intersemiotic cohesion in a subtitled filmic text connecting subtitles with other semiotic components of a film and thus sustaining the linguistically visual whole.

There are many things that remain for further research on the investigation of meaning-making processes in a subtitled filmic text and the 
mechanisms of typography in subtitling should be detailed. Naturally, a greater level of analytical delicacy is always possible.

\section{BIBLIOGRAPHY}

ANISIMOVA, E.E. (2003), Text Linguistics and Crosscultural Communication (a case study of creolized texts), Moscow, Academia.

BALdRY, A., THIBAult, P.J. (2006), Multimodal Transcription and Text Analysis: A Multimedia Toolkit and Coursebook, London/Oakville, Equinox.

CHAume, F. (2004), “Film Studies and Translation Studies: Two Disciplines at Stake in Audiovisual Translation", Meta: Translators' Journal, vol. 49, 1: 12-24.

Diaz CinTAS, J., Remael, A. (2007), Audiovisual Translation: Subtitling, Manchester, St. Jerome.

GotTlieb, H. (2005), “Texts, Translation and Subtitling: In Theory, and in Denmark”, Screen Translation. Eight Studies in Subtitling, Dubbing and Voice-over, Copenhagen, University of Copenhagen, 1-40.

Karamitroglou, F. (1997), "Proposed Set of Subtitling Standards in Europe", Translation Journal, 2(2). [Access: 8 May 2016]. Available at: <http://www.bokorlang.com/journal/04stndrd.htm>.

KRESS, G., VAN LEEUWEN, T. (2006), Reading Images: The Grammar of Visual Design, $2^{\text {nd }}$ ed. London, Routledge.

LEMKE, J. (2002), “Travels in Hypermodality”, Visual Communication, vol. 1(3), 299-325.

MCClaRtY, R. (2012), "Towards a Multidisciplinary Approach in Creative Subtitling", MonTI 4, 133-53.

NikOlaeva, T.M. (1998), "Paralinguistics", Linguistics. Great Encyclopedic Dictionary, Ch. Ed., V.N. Yartseva, Moscow, Great Russian Encyclopedia.

Pedersen, J. (2005), "How is culture rendered in subtitles?", MuTra 2005 - Challenges of Multidimensional Translation: Conference Proceedings. Available at: $<$ http://www.euroconferences.info/proceedings/2005 Proceedings/2005 Pedersen Jan.pdf $>$

VAN LeEUWEN, T. (2006), "Towards a Semiotics of Typography", Information Design Journal + Document Design 14(2), John Benjamins Publishing Company, 139-155.

ZIYAZOVA, I.R. (2015), "Semiotic Cohesion in a Subtitled Filmic Text", The Magic of Innovation: New Trends in Language Research and Teaching Foreign Languages: Conference Proceedings, 24-25 April, Moscow, MGIMO University, 582-587. 